\title{
Qualidade fisiológica de sementes de berinjela osmocondicionadas submetidas à secagem
}

\author{
Rodrigo de Góes Esperon Reis(1), Renato Mendes Guimarães ${ }^{(1)}$, Diego de Sousa Pereira(1), \\ Matheus Bornelli de Castro(1), Antônio Rodrigues Vieira ${ }^{(2)}$ e Maria Laene Moreira de Carvalho(1)
}

(1)UniversidadeFederal de Lavras, CaixaPostal3037,CEP37200-000Lavras, MG, Brasil.E-mail:guidegoes@gmail.com, renatomg@dag.ufla.br, diegobizi@gmail.com, matheusbornellicastro@gmail.com, laene@dag.ufla.br (2)Empresa de Pesquisa Agropecuária de Minas Gerais, Centro Tecnológico do Sul de Minas, Campus da Ufla, Caixa Postal 176, CEP 37200-000 Lavras, MG, Brasil. E-mail: arvieira@epamig.ufla.br

Resumo-O objetivo deste trabalho foi avaliar a qualidade fisiológica de sementes de berinjela osmocondicionadas submetidas à secagem. Utilizaram-se sementes de berinjela, cultivar Embu, condicionadas em solução aerada de $\mathrm{KNO}_{3}(-0,8 \mathrm{MPa})$, a $25^{\circ} \mathrm{C}$, por 48 horas. As sementes foram submetidas aos seguintes procedimentos: redução do teor de água inicial (r), choque térmico (CT) e secagem lenta (SL) ou rápida (SR) por 48 horas. As combinações desses procedimentos constituíram os tratamentos: sementes condicionadas e sem secagem, SL, SR, CTSL, CTSR, rSL, rSR, rCTSL e rCTSR, além da testemunha (sementes sem condicionamento). As sementes condicionadas e as secas lentamente expressaram maior percentagem de germinação. Não houve diferença entre os tratamentos quanto à percentagem de emergência de plântulas. A testemunha levou mais tempo para alcançar a máxima emergência do que os demais tratamentos. As sementes submetidas ao choque térmico apresentaram maiores valores de condutividade elétrica do que as que não passaram por esse tratamento. A qualidade fisiológica das sementes de berinjela obtida com o condicionamento é mantida após a secagem. A secagem de sementes de berinjela condicionadas deve ser realizada preferencialmente de forma lenta, com ou sem redução do teor de água inicial.

Termos para indexação: Solanum melongena, atividade enzimática, condicionamento fisiológico, microscopia eletrônica de varredura.

\section{Physiological quality of osmoprimed eggplant seeds subjected to drying}

\begin{abstract}
The objective of this work was to evaluate the physiological quality of osmoprimed eggplant seeds subjected to drying. Eggplant seeds of the cultivar Embu, primed in aerated $\mathrm{KNO}_{3}(-0.8 \mathrm{MPa}$ ) solution, at $25^{\circ} \mathrm{C}$, for 48 hours, were used. The seeds were subjected to the following procedures: reduction of initial moisture content (r), heat shock (CT), and slow (SL) or fast drying (SR) for 48 hours. The combination of these procedures formed the treatments: primed seeds without drying, SL, SR, CTSL, CTSR, rSL, rSR, rCTSL, and rCTSR, besides a control (seeds without priming). Seeds primed and those dried slowly expressed higher germination percentage. No difference was observed among treatments for seedling emergence percentage. The control took more time to express maximum emergence than the other treatments. Seeds subjected to heat shock presented higher values of electrical conductivity than those that did not undergo this treatment. The physiological quality of eggplant seeds gained with priming is maintained after drying. The drying of primed eggplant seeds should be preferably performed slowly, with or without reduction of initial moisture content.
\end{abstract}

Index terms: Solanum melongena, enzymatic activity, physiological priming, scanning electron microscopy.

\section{Introdução}

A absorção de água é processo essencial para que ocorram reparos de danos em sementes e o início da germinação. O condicionamento fisiológico de sementes consiste em hidratação parcial, o que permite que os processos preparatórios para a germinação sejam iniciados, evita a protrusão da raiz primária e, quando semeadas, promove a germinação de forma rápida e uniforme (Santos et al., 2008; Varier et al., 2010), além de proporcionar tolerância a estresses (Nascimento \& Aragão, 2004; Ashraf \& Foolad, 2005).

Em lotes de sementes de berinjela, diferentes pesquisadores concluíram que o condicionamento fisiológico é eficaz para melhorar o vigor da planta (Fanan \& Novembre, 2007; Nascimento \& Lima, 2008; Reis et al., 2012). No entanto, esse tratamento apresenta limitações, como: a necessidade de secagem para facilitar o manuseio, a semeadura e o armazenamento das sementes (Demir et al., 2005); 
e a redução acentuada da longevidade em algumas espécies (Sivasubramaniam et al., 2011).

Os efeitos benéficos adquiridos com o condicionamento fisiológico podem ser revertidos, dependendo do método de secagem utilizado (Butler et al., 2009; Caseiro \& Marcos Filho, 2005). Assim, a secagem deve ser realizada de modo que não ocorra perda ou alteração significativa do efeito do condicionamento.

A tolerância à dessecação em sementes ortodoxas está ligada a diferentes mecanismos, como o acúmulo de proteínas protetoras, a presença de sistemas antioxidantes ativos e mecanismos de reparo durante a reidratação das sementes (Chakrabortee et al., 2007), os quais são importantes na prevenção de danos oxidativos e na manutenção da estrutura de macromoléculas e membranas.

Os procedimentos utilizados para a reindução de tolerância à dessecação em sementes são similares àqueles propostos para prevenir a redução da longevidade em sementes condicionadas, e os mecanismos fisiológicos que regulam esses atributos podem ser os mesmos, pois a tolerância à dessecação e a longevidade são estreitamente relacionadas (Caseiro \& Marcos Filho, 2005).

Diversos pesquisadores estudaram os efeitos de métodos alternativos de secagem de sementes condicionadas na qualidade e na longevidade de sementes (Lin et al., 2005; Schwember \& Bradford, 2005; Soeda et al., 2005). Constatou-se que esses métodos estão relacionados à reativação de mecanismos de proteção das sementes; que a incubação em altas temperaturas induz à síntese de proteínas de choque térmico (Butler et al., 2009); e que a secagem lenta favorece a síntese de proteínas "late embryogenesis abundant" - LEA (Butler et al., 2009), que atuam na estabilização de membranas durante a secagem de sementes (Buitink \& Leprince, 2008).

As enzimas do sistema antioxidante são responsáveis pela proteção contra as espécies reativas de oxigênio (EROs). Como exemplo, tem-se a enzima superóxido dismutase (SOD), que realiza a dismutação do radical superóxido $\left(\mathrm{O}_{2}^{-}\right)$em $\mathrm{O}_{2}$ e $\mathrm{H}_{2} \mathrm{O}_{2}$, sendo considerada a primeira linha de defesa contra as EROs (Carvalho, 2008). A enzima catalase (CAT) catalisa a reação de decomposição da molécula de $\mathrm{H}_{2} \mathrm{O}_{2}$ em $\mathrm{H}_{2} \mathrm{O}$ e $\mathrm{O}_{2}$ (Barreiros et al., 2006).

Esses sistemas de proteção atuam em conjunto, o que evita ou reduz os danos causados às células. Quando não funcionam de maneira adequada, acarretam reduções na qualidade fisiológica ou na perda de viabilidade, causadas por injúrias que ocorrem em membranas, as quais são alvos potenciais para danos provocados por métodos de secagem inadequados (Silva et al., 2007).

O objetivo deste trabalho foi avaliar a qualidade fisiológica de sementes de berinjela osmocondicionadas submetidas à secagem.

\section{Material e Métodos}

O experimento foi conduzido no Laboratório Central de Sementes e nos laboratórios de Bioquímica e Fisiologia Molecular de Plantas e de Microscopia Eletrônica da Universidade Federal de Lavras, MG, de agosto a dezembro de 2012.

Foram utilizadas sementes de berinjela (Solanum melongena L.), cultivar Embu, produzidas em 2007, pela HortiAgro Sementes Ltda., em Ijaci, MG. As sementes foram acondicionadas em embalagem de papel Kraft e armazenadas em câmara fria $\left(15^{\circ} \mathrm{C}\right.$ e $55 \%$ de UR), onde permaneceram até o início do experimento.

Aproximadamente $200 \mathrm{~g}$ de sementes foram submetidas ao condicionamento fisiológico em solução aerada de $\mathrm{KNO}_{3}(-0,8 \mathrm{MPa})$, a $25^{\circ} \mathrm{C}$, por 48 horas, com fotoperíodo de 8 horas (Reis et al., 2012).

Após a remoção do excesso de água, as sementes pesavam, aproximadamente, $300 \mathrm{~g}$, foram divididas em dez porções de $30 \mathrm{~g}$ e submetidas à combinação dos seguintes procedimentos: redução do teor de água inicial, choque térmico e secagem lenta ou rápida.

As porções de sementes que passaram pela redução do teor de água inicial foram pesadas em balança de precisão $\pm 0,001$ g, modelo TP200s (Ohaus, Parsippany, NJ, EUA) e permaneceram sob condições ambientais até redução de $10 \%$ do peso inicial. Para a aplicação do choque térmico, as sementes foram acondicionadas em embalagens herméticas e colocadas em banho-maria sem circulação, modelo CT-245 (Cientec, Charqueada, $\mathrm{SP}$ ), a $36^{\circ} \mathrm{C}$, durante 1 hora. A secagem lenta foi realizada em câmara do tipo BOD, modelo 347-CDG (Eletrolab, São Paulo, SP), com temperatura de $25^{\circ} \mathrm{C}$ e UR de $60 \%$, por 48 horas. A secagem rápida ocorreu em estufa com circulação forçada de ar, a $32^{\circ} \mathrm{C}$ e $45 \%$ de UR, por 48 horas.

A combinação dos procedimentos descritos acima constituiu os tratamentos: sementes condicionadas e sem secagem; secagem lenta; secagem rápida; choque térmico + secagem lenta; choque térmico + 
secagem rápida; redução do teor de água + secagem lenta; redução do teor de água + secagem rápida; redução do teor de água + choque térmico + secagem lenta; e redução do teor de água + choque térmico + secagem rápida; além da testemunha (sementes sem condicionamento).

A curva de secagem das sementes foi obtida apenas para a secagem lenta e rápida. Para tanto, quatro amostras de $0,5 \mathrm{~g}$, para cada tipo de secagem, foram pesadas em balança de precisão $\pm 0,001 \mathrm{~g}$, modelo TP200s (Ohaus, Parsippany, NJ, EUA), nos seguintes intervalos: $2,4,6,8,10,12,16,20,24,30,36,42 \mathrm{e}$ 48 horas. O teor de água (base seca) das sementes foi avaliado após 24 horas, pelo método de estufa a $105^{\circ} \mathrm{C}$ (Regras para análise de sementes, 2009), e a velocidade de secagem foi calculada em pontos percentuais por hora $\left(\mathrm{pp} \mathrm{h}^{-1}\right)$.

O teor de água foi avaliado antes e depois do condicionamento fisiológico e após a secagem das sementes. Para cada tratamento, foram utilizadas três amostras de $0,5 \mathrm{~g}$ de sementes avaliadas pelo método de estufa a $105^{\circ} \mathrm{C}$ (Regras para análise de sementes, 2009). Os resultados foram apresentados em percentagem, com base na massa úmida.

$\mathrm{Na}$ avaliação da percentagem de germinação, foram utilizadas quatro repetições de 50 sementes semeadas em caixas de acrílico transparente $(11 \times 11 \mathrm{~cm})$, sobre duas folhas de papel mata-borrão umedecidas com volume de água destilada equivalente a 2,5 vezes o peso seco do papel. As caixas foram mantidas em câmaras do tipo BOD, modelo 347-CDG (Eletrolab, São Paulo, SP), com temperatura alternada de $20-30^{\circ} \mathrm{C}$ e fotoperíodo de 8 horas, durante 14 dias (Regras para análise de sementes, 2009).

Para o teste de emergência de plântulas, foram utilizadas quatro repetições de 50 sementes semeadas em bandejas de plástico contendo areia e terra $(2: 1 \mathrm{v} / \mathrm{v})$ umedecida $(60 \%$ da capacidade de retenção do substrato), mantidas em câmara de crescimento com temperatura de $25^{\circ} \mathrm{C}$ e fotoperíodo de 8 horas, durante 21 dias. Foram realizadas avaliações diárias das plântulas emergidas, tendo-se determinado a percentagem e o tempo médio de emergência (Labouriau, 1983).

Para a avaliação da condutividade elétrica de massa ( $\mu \mathrm{S} \mathrm{cm} \mathrm{cm}^{-1} \mathrm{~g}^{-1}$ de semente), foram utilizadas quatro repetições de $0,5 \mathrm{~g}$ de sementes, imersas em $20 \mathrm{~mL}$ de água deionizada, a $25^{\circ} \mathrm{C}$, por 24 horas, de acordo com Rudrapal \& Nakamura (1988), com avaliação da condutividade elétrica da solução em condutivímetro DM-32 (Digimed, São Paulo, SP).

Para a estimativa da atividade do sistema antioxidante, o extrato enzimático foi obtido pela maceração de 0,2 $\mathrm{g}$ de sementes em presença de nitrogênio líquido e polivinilpirrolidona (PVP), aos quais foram adicionados $1,5 \mathrm{~mL}$ do tampão de extração $\left(1,47 \mathrm{~mL}\right.$ de tampão fosfato de potássio $0,1 \mathrm{~mol} \mathrm{~L}^{-1}$, $\mathrm{pH} 7,0 ; 15 \mu \mathrm{L}$ de EDTA $0,1 \mathrm{~mol} \mathrm{~L}^{-1}, \mathrm{pH} 7,0$; e ácido ascórbico $\left.0,001 \mathrm{~mol} \mathrm{~L}^{-1}\right)$. $\mathrm{O}$ extrato permaneceu 12 horas em geladeira, quando foi centrifugado a $13.000 \mathrm{~g}$ por $10 \mathrm{~min}, \mathrm{a} 4^{\circ} \mathrm{C}$. O sobrenadante coletado foi utilizado nas análises enzimáticas da SOD (EC 1.15.1.1) e da CAT (EC 1.11.1.6), tendo sido aplicado em microplacas de Elisa de 96 poços, em triplicatas. A atividade da SOD foi avaliada conforme proposto por Giannopolitis \& Ries (1977), com modificações. Adicionaram-se $10 \mu \mathrm{L}$ do extrato enzimático em placa de acrílico UV e $190 \mu \mathrm{L}$ do meio de incubação [tampão de fosfato de potássio $50 \mathrm{mmol} \mathrm{L}^{-1}$, $\mathrm{pH} 7,8$; metionina $14 \mathrm{mmol} \mathrm{L}^{-1}$; EDTA $0,1 \mu \mathrm{mol} \mathrm{L} \mathrm{L}^{-1}$; nitroblue tetrazolium (NBT) $75 \mu \mathrm{mol} \mathrm{L}^{-1}$; e riboflavina $2 \mu \mathrm{mol} \mathrm{L} \mathrm{L}^{-1}$. A microplaca contendo o meio de incubação e a amostra foram iluminadas com lâmpada fluorescente de $20 \mathrm{~W}$ por $10 \mathrm{~min}$. As leituras foram realizadas a $560 \mathrm{~nm}$, em espectrofotômetro de microplacas Epoch (Biotek, Winooski, VT, EUA). Uma unidade da SOD corresponde à quantidade de enzima capaz de inibir em $50 \%$ a fotorredução do NBT nas condições do ensaio. A atividade da CAT foi avaliada de acordo com Havir \& McHale (1987). A atividade da enzima foi determinada pelo decréscimo na absorbância a $240 \mathrm{~nm}$, a cada $15 \mathrm{~s}$, por $3 \mathrm{~min}$, monitorado pelo consumo de peróxido de hidrogênio, pelo espectrofotômetro de microplacas Epoch (Biotek, Winooski, VT, EUA). O coeficiente de extinção molar utilizado foi de $36 \mathrm{mmol} \mathrm{L}^{-1} \mathrm{~cm}^{-1}$ corrigido para $18 \mathrm{mmol} \mathrm{L}^{-1} \mathrm{~cm}^{-1}$, dado que os poços da placa UV apresentam $0,5 \mathrm{~cm}$ de comprimento.

Para a eletroforese de proteínas resistentes ao calor, foram macerados $100 \mathrm{mg}$ de cada amostra, em cadinhos, em presença de PVP e nitrogênio líquido. Adicionou-se tampão de extração [Tris base $50 \mathrm{mmol} \mathrm{L}^{-1}, \mathrm{pH} 7,5 ; \mathrm{NaCl} 0,5 \mathrm{~mol} \mathrm{~L}^{-1} ; \mathrm{MgCl}_{2}$

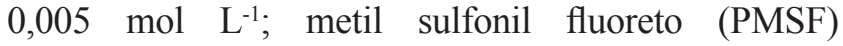
$0,001 \mathrm{~mol} \mathrm{~L}^{-1}$; água destilada; e $\beta$-mercaptoetanol $0,1 \%$ ], na proporção de dez partes de tampão para uma de amostra (Alfenas et al., 1991). As amostras foram centrifugadas (MPW Med. Instruments, Varsóvia, 
Polônia) a $11.000 \mathrm{~g}$ por $30 \mathrm{~min}, \mathrm{a} 4^{\circ} \mathrm{C}$. O sobrenadante foi separado e incubado em banho-maria, a $85^{\circ} \mathrm{C}$, por $15 \mathrm{~min}$, e, em seguida, centrifugado novamente, como descrito acima. Um total de $70 \mu \mathrm{L}$ do sobrenadante foi coletado, colocado em microtubos de $2 \mathrm{~mL}$ com um furo na tampa, tendo-se acrescentado $40 \mu \mathrm{L}$ do tampão da amostra (2,5 mL de glicerol; 0,46 $\mathrm{g}$ de dodecil sulfato de sódio - SDS; e $20 \mathrm{mg}$ de azul de bromofenol), e transferido para água fervente, durante 5 min. Foram aplicados $50 \mu \mathrm{L}$ da amostra em gel de poliacrilamida SDS-Page a $6 \%$ (gel concentrador) e 12,5\% (gel separador). A corrida eletroforética, em cuba vertical, modelo 600-15-1.5 (Hoefer, Inc., Holliston, MA, EUA), foi realizada a $150 \mathrm{~V}$ por 6 horas (Alfenas et al., 1991). A coloração dos géis foi feita com uso de solução de Coomassie Blue R-250 0,05\% (Sigma-Aldrich, Steinheim, Alemanha), por 12 horas, e de solução de ácido acético e álcool etílico, para descoloração.

Para a análise ultraestrutural, foram retiradas 20 sementes de cada tratamento. As sementes foram colocadas em fixador primário Karnovsky modificado (glutaraldeído 2,5\%; formaldeído 2,5\% em tampão cacodilato de sódio $0,05 \mathrm{~mol} \mathrm{~L}^{-1}, \mathrm{pH} 7,2$; e $\mathrm{CaCl}_{2}$ $0,001 \mathrm{~mol} \mathrm{~L}^{-1}$ ), onde permaneceram por 48 horas, e, em seguida, em glicerol $30 \%$, por $30 \mathrm{~min}$. As sementes foram cortadas transversalmente com bisturi em nitrogênio líquido e lavadas em água destilada, seguindo-se fixação secundária em tetróxido de ósmio 1\% (três gotas por amostra), em tampão cacodilato

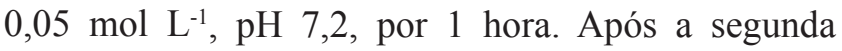
fixação, os cortes das sementes foram lavados em água destilada por três vezes e submetidos à desidratação em gradiente de acetona a 25, 50, 75, 90 e $100 \%$, durante 10 min cada um. Uma vez desidratado, o material foi submetido à secagem ao ponto crítico, no secador CPD 030 (Leica Microsystems, Wetzlar, Alemanha), e a posterior banho de ouro no evaporador SCD 050 (Leica Microsystems, Wetzlar, Alemanha). A visualização das amostras para verificação da integridade do sistema de membranas foi realizada em microscópio eletrônico de varredura LEO Evo 40 (Carl Zeiss, Jena, Alemanha).

Utilizou-se o delineamento experimental inteiramente casualizado, com quatro repetições, para as variáveis de qualidade fisiológica, e com três repetições, para as análises enzimáticas. Os dados foram submetidos a análise de variância e quando o teste $\mathrm{F}$ foi significativo, as médias foram comparadas pelo teste de Scott \& Knott, a 5\% de probabilidade. Para a condutividade elétrica, também foi realizado o teste de Scheffé, a 5\% de probabilidade, para comparar os tratamentos com e sem choque térmico.

\section{Resultados e Discussão}

O teor de água (base seca) das sementes submetidas à secagem rápida foi reduzido de 72,3 para $19,9 \%$ após 1 hora, o que corresponde a uma velocidade de secagem de 52,4 $\mathrm{pp} \mathrm{h}^{-1}$ (Figura 1 A). Nas cinco horas seguintes, o decréscimo foi menos acentuado, com velocidade de secagem de 2,4 $\mathrm{pp} \mathrm{h}^{-1}$. A umidade das sementes variou em razão da flutuação da umidade relativa do ar e finalizou em 7,4\% após 48 horas de secagem.

Para a secagem lenta, a velocidade de secagem foi modificada ao longo do período considerado. No início do processo as sementes estavam com teor de água de $69,9 \%$ e atingiram $40,3 \%$ na primeira hora, com velocidade de secagem de 29,6 $\mathrm{pp} \mathrm{h}^{-1}$, valor inferior àquele observado para a secagem rápida. Após mais 1 hora de secagem, a umidade das sementes chegou a $29,4 \%$ de umidade, com redução de $10,9 \mathrm{pp} \mathrm{h}^{-1}$. Nas horas subsequentes, a velocidade de secagem diminuiu ao longo do tempo. Após 12 horas, a umidade das sementes atingiu $12,6 \%$, e esse valor passou por pequenas alterações nas 36 horas seguintes e chegou a $12,4 \%$.

Quando as sementes estão mais hidratadas, a perda de água inicial é mais rápida, uma vez que a água preenche os espaços intercelulares e dilui o conteúdo celular (Vertucci \& Farrant, 1995). De acordo com estes autores, quando o grau de umidade é inferior a $20 \%$, a água presente está ligada aos compostos da semente por meio de ligações químicas, como pontes de hidrogênio e ligações iônicas, e participa da constituição da semente, sendo de difícil remoção.

Inicialmente, as sementes apresentavam 9,2\% de teor de água e, após o condicionamento fisiológico, 38,4\% (Figura $1 \mathrm{~B}$ ). Depois da secagem lenta, as sementes atingiram teores de água entre 9,3 e 9,5\%, enquanto, na secagem rápida, a umidade foi reduzida a valores entre 7,0 e 7,5\%. Como cada tipo de secagem foi realizado com temperaturas e umidades relativas diferentes, os graus de umidade encontrados são referentes ao teor de água no equilíbrio higroscópico, como também foi observado por Demir et al. (2005), em sementes de pimentão (Capsicum annuum).

As sementes condicionadas e as condicionadas e submetidas à secagem lenta expressaram as maiores percentagens de germinação, de 96 e 97\% (Figura 2 A). 

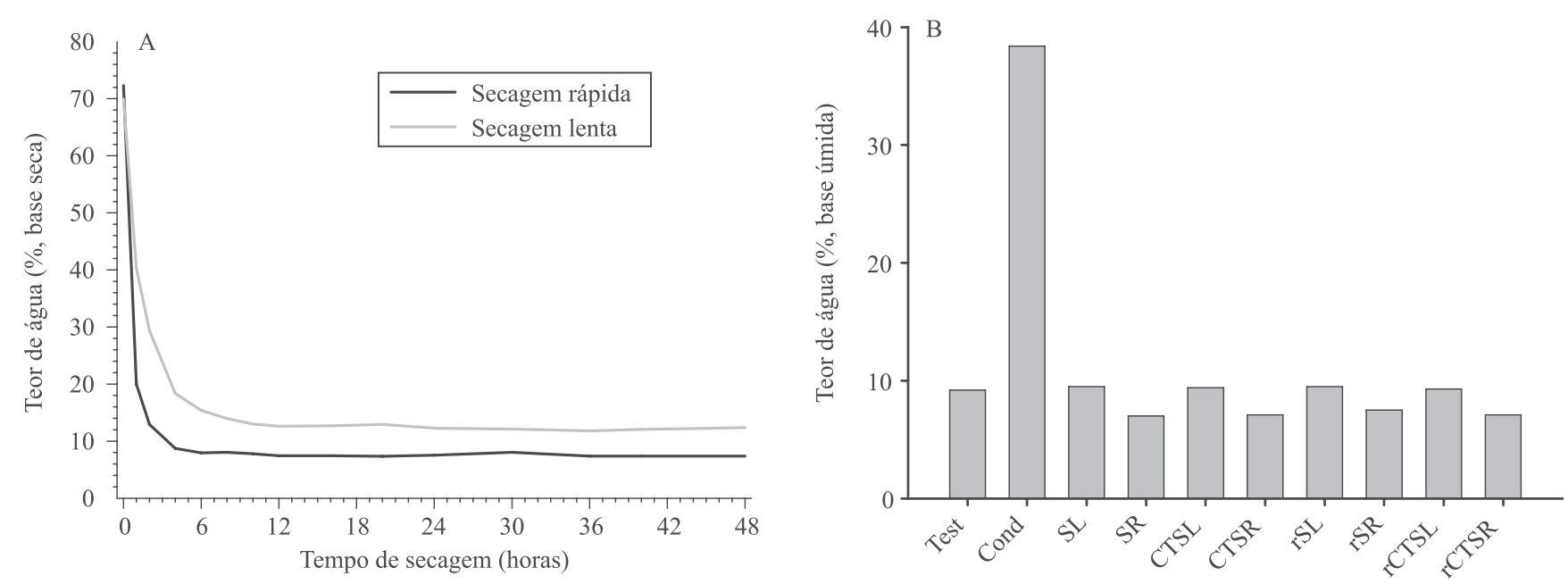

Figura 1. Curva de secagem (A) e teor de água (B) de sementes de berinjela 'Embu' submetidas à secagem rápida (SR) e lenta (SL) e a diferentes métodos de secagem, respectivamente, após condicionamento fisiológico. Test, testemunha (sementes sem condicionamento); Cond, sementes condicionadas sem secagem; CT, choque térmico; r, redução do teor de água.
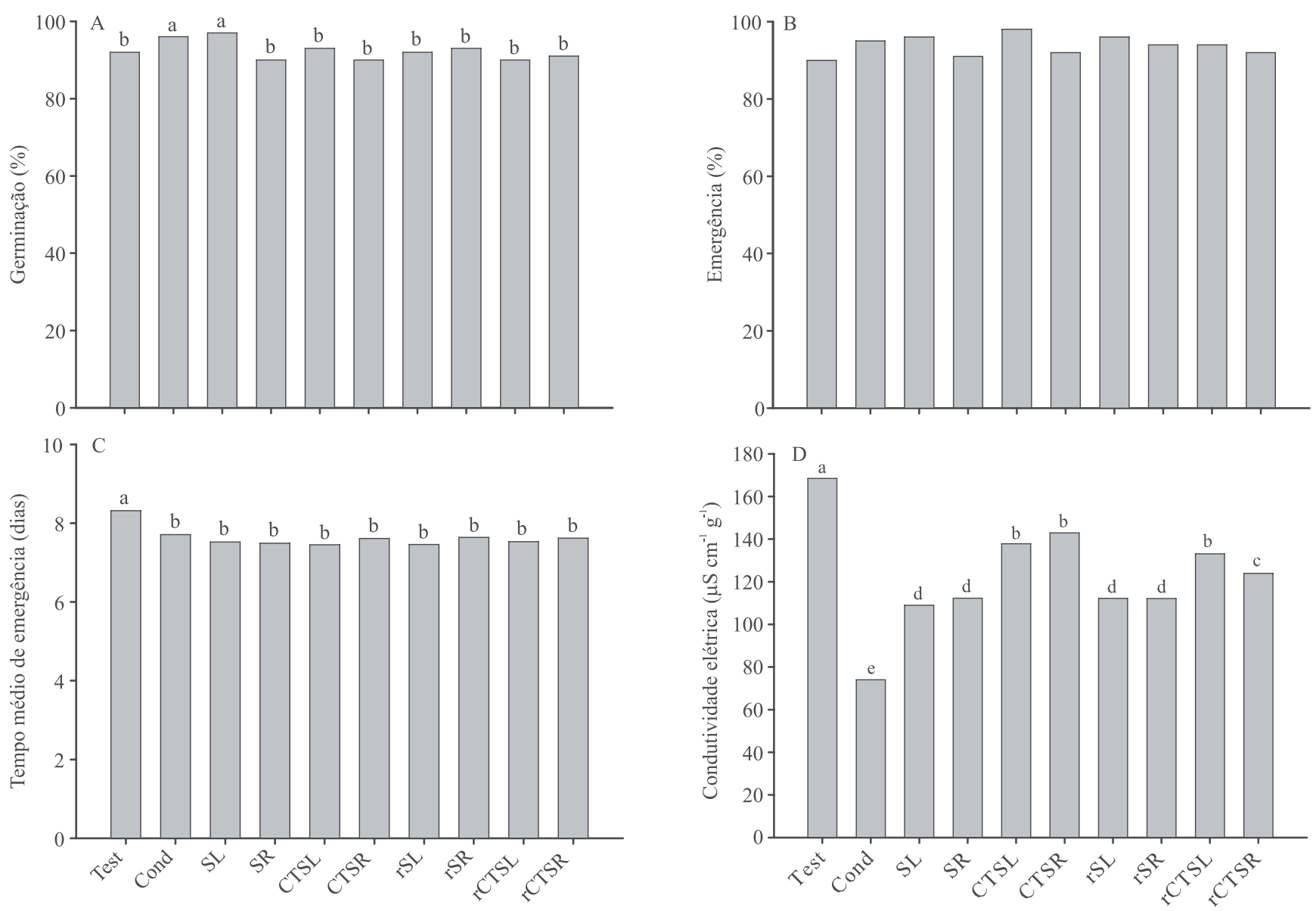

Figura 2. Percentagem de germinação (A), percentagem (B) e tempo médio de emergência (C), e condutividade elétrica (D) de sementes de berinjela 'Embu' submetidas a diferentes métodos de secagem após condicionamento fisiológico. Médias seguidas por letras iguais não diferem pelo teste de Scott \& Knott, a 5\% de probabilidade. Test, testemunha (sementes sem condicionamento); Cond, sementes condicionadas sem secagem; SL, secagem lenta; SR, secagem rápida; CT, choque térmico; r, redução do teor de água. 
Os demais tratamentos apresentaram média de 91\% de germinação. Quando um lote de sementes apresenta elevada qualidade fisiológica e é submetido a diferentes tratamentos, o teste de germinação pode não ser sensível para detectar diferenças dos efeitos dos tratamentos, como foi verificado por Rudrapal \& Nakamura (1988) e Caseiro \& Marcos Filho (2005). Entretanto, o condicionamento fisiológico proporcionou incrementos na percentagem de plântulas normais, o que indicou reparo de danos presentes nas sementes. Da mesma forma, as sementes condicionadas e submetidas à secagem lenta também se destacaram quanto à germinação, pois os benefícios obtidos com o condicionamento foram mantidos nesse tratamento.

Quanto à percentagem de emergência de plântulas (Figura 2 B), não houve diferença entre os tratamentos, com média igual a $94 \%$. Esse resultado é indicativo de que, em relação à testemunha, embora não tenham ocorrido incrementos significativos na emergência de plântulas após os tratamentos, os métodos de secagem não prejudicaram o estande final avaliado no vigésimo primeiro dia após a semeadura. Demir et al. (2005) observaram resultados diferentes para sementes de pimentão, em que a secagem lenta proporcionou maior percentagem de emergência do que a secagem rápida.

Apesar de não ter sido encontrada diferença expressiva entre os tratamentos para percentagem de emergência de plântulas, ao se avaliar o tempo médio de emergência (Figura $2 \mathrm{C}$ ), as sementes condicionadas ou condicionadas e submetidas a algum método de secagem não diferiram entre si e exibiram a máxima emergência em menor tempo (7,6 dias) do que a testemunha (8,3 dias). Esses resultados corroboram os obtidos por Caseiro \& Marcos Filho (2005), para sementes de cebola (Allium cepa), que relataram que não houve reversão dos efeitos benéficos do condicionamento quando as sementes foram submetidas a diferentes métodos de secagem.

Com relação à condutividade elétrica, a testemunha apresentou o maior valor $\left(168,45 \mu \mathrm{S} \mathrm{cm}^{-1} \mathrm{~g}^{-1}\right)$, e as sementes condicionadas sem secagem, o menor (74,01 $\left.\mu \mathrm{S} \mathrm{cm}^{-1} \mathrm{~g}^{-1}\right)$ (Figura $2 \mathrm{D}$ ), o que se deve ao maior teor de água dessas sementes $(38,4 \%)$. Resultados similares foram observados por Caseiro \& Marcos Filho (2005), ao avaliar sementes de cebola.

Entre as sementes que passaram por algum tipo de secagem após o condicionamento fisiológico, destacaram-se dois grupos: sementes que não foram submetidas ao choque térmico e sementes que passaram pelo choque térmico. $\mathrm{O}$ primeiro grupo apresentou menor média $\left(111,39 \mu \mathrm{S} \mathrm{cm}^{-1} \mathrm{~g}^{-1}\right)$ do que o segundo $\left(134,46 \mu \mathrm{S} \mathrm{cm}^{-1} \mathrm{~g}^{-1}\right)$. Os maiores valores encontrados na condutividade elétrica indicaram a ocorrência de danos ao sistema de membranas celulares das sementes. Caseiro \& Marcos Filho (2005) também verificaram maiores valores no teste de condutividade elétrica, quando sementes de cebola foram submetidas ao choque térmico em banho-maria.

Quanto à atividade da enzima SOD, não foi encontrada diferença significativa entre os tratamentos (Figura 3 A). Sedghi (2013) não observou diferenças para a atividade dessa enzima entre sementes de calêndula (Callendula officinalis), condicionadas e condicionadas e secas a 20 e $30^{\circ} \mathrm{C}$. Contudo, Chen \& Arora (2011) relataram maior atividade da SOD em sementes de espinafre (Spinacia oleracea) secas (testemunha) do que após o condicionamento; já as sementes condicionadas e submetidas à secagem apresentaram valores intermediários.

As sementes condicionadas sem secagem apresentaram menor atividade de CAT, em comparação aos demais tratamentos, exceto as sementes submetidas à redução do teor de água, seguida de secagem lenta (Figura 3 B). Esses resultados confirmam os de Chen \& Arora (2011), que constataram maior atividade dessa enzima em sementes secas (testemunha) do que após o condicionamento; quando as sementes condicionadas foram secas, houve incrementos na atividade da CAT, mas os valores encontrados permaneceram inferiores aos das sementes sem condicionamento. De acordo com esses mesmos autores, a atividade do sistema antioxidante pode ser reduzida nos estágios iniciais da germinação. Assim, durante o condicionamento fisiológico, no qual ocorre hidratação parcial das sementes para início dos processos preparatórios para a germinação, também se observa essa redução. Em sementes secas após o condicionamento e submetidas a estresses oxidativos, os mecanismos de proteção contra as EROs são novamente necessários, com ocorrência de incrementos na atividade de enzimas do sistema antioxidante.

A SOD e a CAT são as principais enzimas envolvidas na manutenção da longevidade das sementes durante o armazenamento, e, durante o condicionamento, é comum observar redução em suas atividades (Chen $\&$ Arora, 2011). No entanto, pode haver melhoria na 
qualidade fisiológica das sementes condicionadas, relacionada à melhoria do funcionamento do sistema antioxidante, com possíveis aumentos nas atividades das enzimas SOD e CAT (Hsu et al., 2003).

Em todos os tratamentos, foram encontradas proteínas com alto e médio peso molecular (Figura 4), que são proteínas LEA, presentes em menor quantidade nas sementes avaliadas. Apesar de essas proteínas serem degradadas durante a hidratação das sementes (Chen \& Arora, 2011), a testemunha também apresentou bandas com baixa intensidade.

Na parte inferior da Figura 4, onde estão localizadas as proteínas com menor peso molecular, observaram-se bandas: em menor intensidade, para a testemunha;
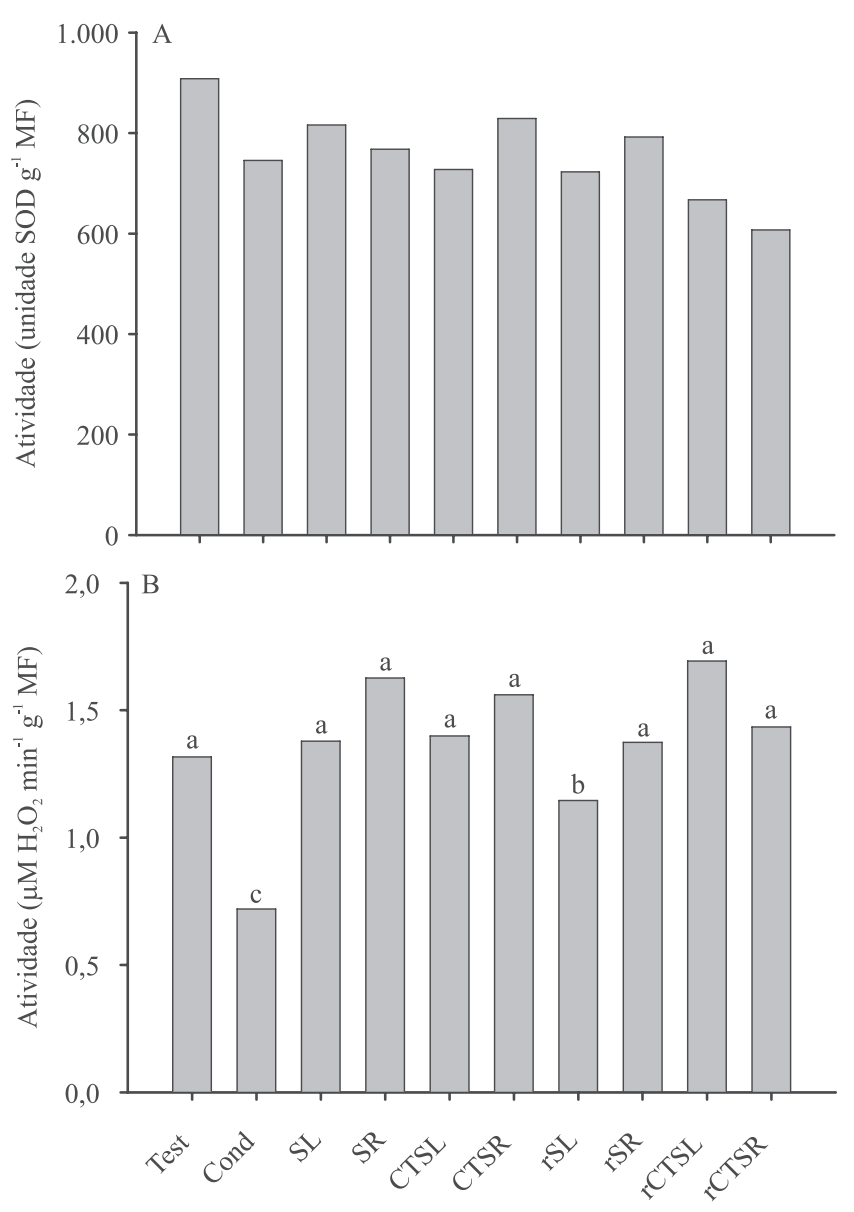

Figura 3. Atividade da enzima superóxido dismutase - SOD (A) e catalase (B) em sementes de berinjela 'Embu' submetidas a diferentes métodos de secagem após condicionamento fisiológico. Test, testemunha (sementes sem condicionamento); Cond, sementes condicionadas sem secagem; SL, secagem lenta; $\mathrm{SR}$, secagem rápida; $\mathrm{CT}$, choque térmico; r, redução do teor de água. em intensidade intermediária, para as sementes condicionadas; e em maior intensidade, para as sementes submetidas à secagem após condicionamento. Essas são proteínas de choque térmico, que são responsáveis pela estabilização da conformação de outras proteínas e estão associadas à viabilidade das sementes durante a maturação e o armazenamento, além de protegerem outras moléculas durante a secagem, o que confere tolerância à dessecação (Wu et al., 2011).

Os dados obtidos pela atividade enzimática e pela eletroforese de proteínas resistentes ao calor estão de acordo com os de Soeda et al. (2005), que constataram que os mecanismos de proteção foram reduzidos durante o condicionamento fisiológico, mas podem ser restaurados após métodos de secagem apropriados.

A análise ultraestrutural das sementes de berinjela indicou que o condicionamento fisiológico favoreceu uma melhor compartimentalização do conteúdo celular (Figura $5 \mathrm{~B}$ ). Nas sementes submetidas à secagem, com ou sem redução do teor de água inicial (Figuras $5 \mathrm{C}$ a $5 \mathrm{~F}$ ), a organização das células ocasionada pelo condicionamento fisiológico foi mantida após a secagem das sementes, o que proporcionou menor condutividade elétrica do que a apresentada pelas sementes submetidas ao choque térmico (Figura 2 D).

Nos tratamentos nos quais foi realizado o choque térmico, houve aglutinação de compostos (destacados com setas nas Figuras $5 \mathrm{G}$ a $5 \mathrm{~J}$ ), provavelmente em razão da desestruturação das membranas de organelas

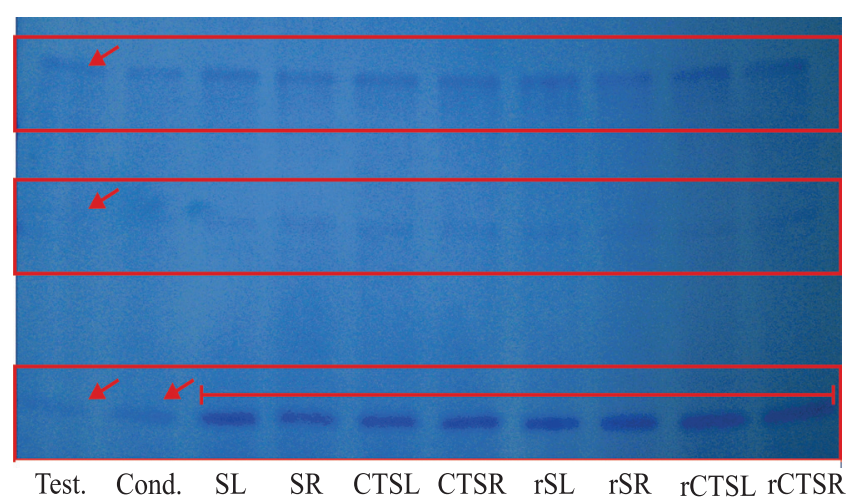

Figura 4. Padrão de proteínas resistentes ao calor de sementes de berinjela 'Embu' submetidas a diferentes métodos de secagem após condicionamento fisiológico. Test, testemunha (sementes sem condicionamento); Cond, sementes condicionadas sem secagem; SL, secagem lenta; $\mathrm{SR}$, secagem rápida; $\mathrm{CT}$, choque térmico; $\mathrm{r}$, redução do teor de água.

Pesq. agropec. bras., Brasília, v.48, n.11, p.1507-1516, nov. 2013 DOI: $10.1590 / \mathrm{S} 0100-204 X 2013001100012$ 

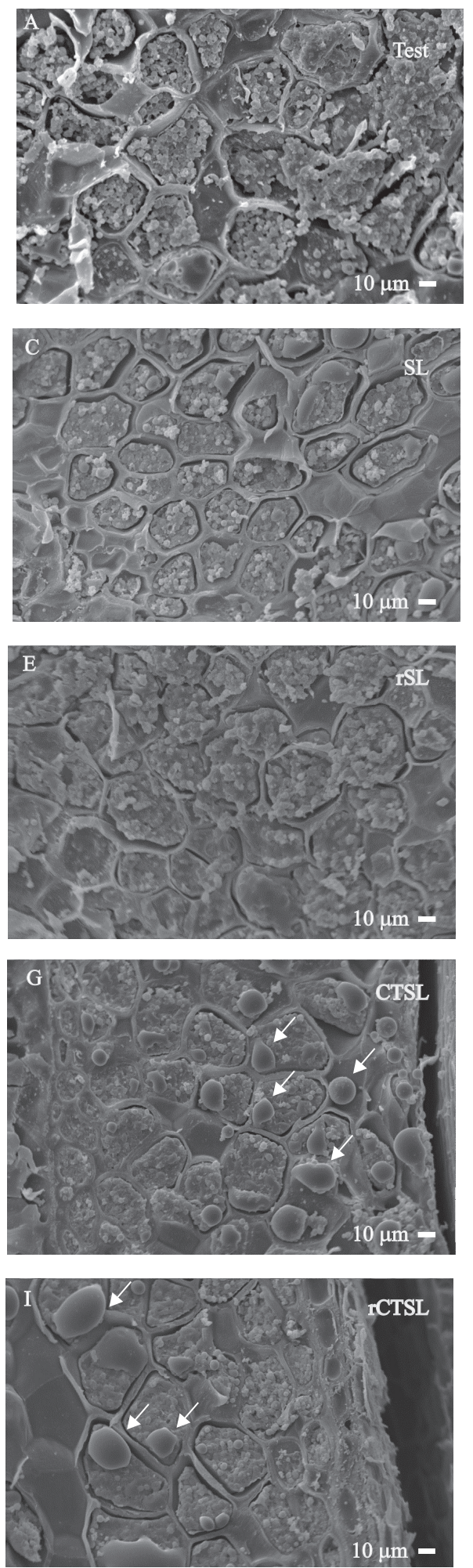
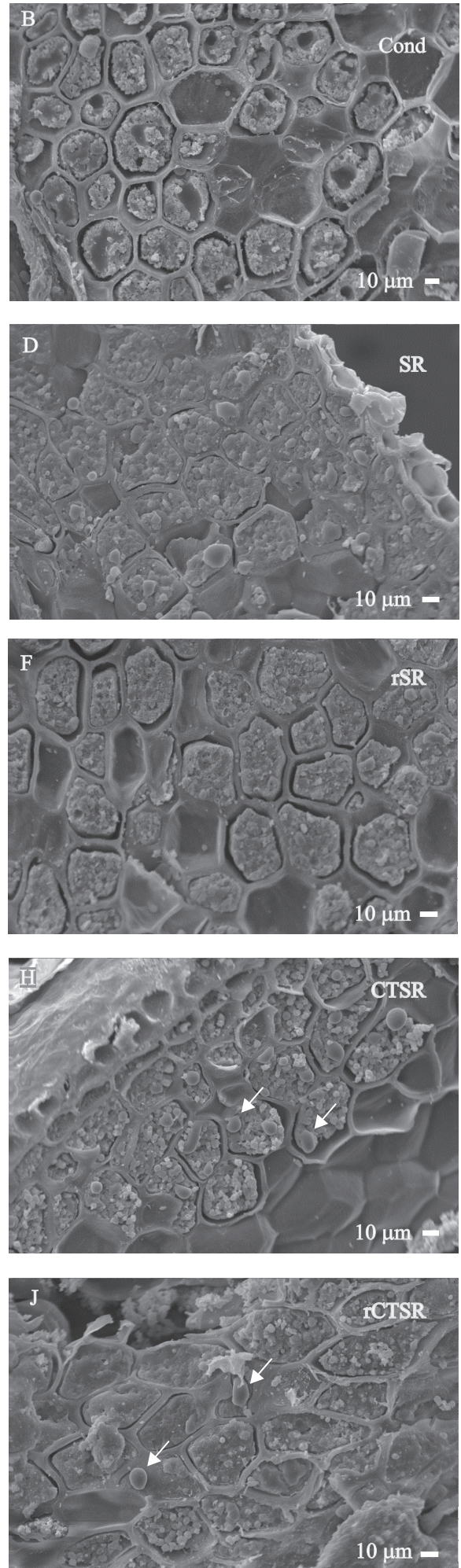

Figura 5. Microscopia eletrônica de varredura do endosperma de sementes de berinjela 'Embu' submetidas a diferentes métodos de secagem. Test, testemunha (sementes sem condicionamento); Cond, sementes condicionadas sem secagem; SL, secagem lenta; SR, secagem rápida; $\mathrm{CT}$, choque térmico; $r$, redução do teor de água. 
celulares. Nas sementes condicionadas e submetidas à combinação de choque térmico e secagem lenta (Figuras 5 G e 5 I), o coalescimento ocorreu em maior grau do que nas sementes que passaram pelo choque térmico, seguido de secagem rápida (Figuras $5 \mathrm{H}$ e $5 \mathrm{~J}$ ).

As injúrias observadas nas imagens estão relacionadas à maior condutividade elétrica verificada para as sementes submetidas ao choque térmico. Esses resultados corroboram os de Silva et al. (2007), que verificaram que a maior incidência de danos estruturais nas membranas proporcionaram os maiores valores de condutividade elétrica de sementes de soja após a secagem.

\section{Conclusões}

1. A qualidade fisiológica das sementes de berinjela osmocondicionadas é mantida após a secagem.

2. A secagem de sementes de berinjela condicionadas deve ser realizada preferencialmente de forma lenta, com ou sem redução do teor de água inicial.

\section{Referências}

ALFENAS, A.C.; PETERS, I.; BRUNE, W.; PASSADOR, G.C. Eletroforese de proteínas e isoenzimas de fungos e essências florestais. Viçosa: Ed. da UFV, 1991. 242p.

ASHRAF, M.; FOOLAD, M.R. Pre-sowing seed treatment - a shotgun approach to improve germination, plant growth, and crop yield under saline and non-saline conditions. Advances in Agronomy, v.88, p.223-271, 2005. DOI: 10.1016/ S0065-2113(05)88006-X.

BARREIROS, A.L.B.S.; DAVID, J.M.; DAVID, J.P. Estresse oxidativo: relação entre geração de espécies reativas e defesa do organismo. Química Nova, v.29, p.113-123, 2006. DOI: 10.1590/ S0100-40422006000100021.

BUITINK, J.; LEPRINCE, O. Intracellular glasses and seed survival in the dry state. Comptes Rendus Biologies, v.331, p.788-795, 2008. DOI: 10.1016/j.crvi.2008.08.002.

BUTLER, L.H.; HAY, F.R.; ELLIS, R.H.; SMITH, R.D.; MURRAY, T.B. Priming and re-drying improve the survival of mature seeds of Digitalis purpurea during storage. Annals of Botany, v.103, p.1261-1270, 2009. DOI: 10.1093/aob/mcp059.

CARVALHO, M.H.C. de. Drought stress and reactive oxygen species. Plant Signaling and Behavior, v.3, p.156-165, 2008. DOI: $10.4161 / \mathrm{psb} .3 .3 .5536$.

CASEIRO, R.F.; MARCOS FILHO, J. Métodos para secagem de sementes de cebola submetidas ao condicionamento fisiológico. Horticultura Brasileira, v.23, p.887-892, 2005. DOI: 10.1590/ S0102-05362005000400005.
CHAKRABORTEE, S.; CHIARA, B.; WALTON, L.J.; SARKAR, S.; RUBINSZTEIN, D.C. Hydrophilic protein associated with desiccation tolerance exhibits broad protein stabilization function. Proceedings of the National Academy of Sciences of the United States of America, v.104, p.18073-18078, 2007. DOI: 10.1073/ pnas.0706964104.

CHEN, K.; ARORA, R. Dynamics of the antioxidant system during seed osmopriming, post-priming germination, and seedling establishment in Spinach (Spinacia oleracea). Plant Science, v.180, p.212-220, 2011. DOI: 10.1016/j.plantsci.2010.08.007.

DEMIR, I.; ERMIS, S.; OKCU, G. Effect of dehydration temperature and relative humidity after priming on quality of pepper seeds. Seed Science and Technology, v.33, p.563-569, 2005.

FANAN, S.; NOVEMBRE, A.D. da L.C. Condicionamento fisiológico de sementes de berinjela. Bragantia, v.66, p.675-683, 2007. DOI: 10.1590/S0006-87052007000400018.

GIANNOPOLITIS, C.N.; RIES, S.K. Superoxide dismutases: I. Occurrence in higher plants. Plant Physiology, v.59, p.309-314, 1977. DOI: $10.1104 /$ pp.59.2.309.

HAVIR, E.A.; MCHALE, N.A. Biochemical and developmental characterization of multiple forms of catalase in tobacco leaves. Plant Physiology, v.84, p.450-455, 1987. DOI: 10.1104/pp.84.2.450.

HSU, C.C.; CHEN, C.L.; CHEN, J.J.; SUNG, J.M. Accelerated aging-enhanced lipid peroxidation in bitter gourd seeds and effects of priming and hot water soaking treatments. Scientia Horticulturae, v.98, p.201-212, 2003. DOI: 10.1016/ S0304-4238(03)00002-5.

LABOURIAU, L.G. A germinação das sementes. Washington: Organização dos Estados Americanos, 1983. 174p.

LIN, R.H.; CHEN, K.Y.; CHEN, C.L.; CHEN, J.J.; SUNG, J.M. Slow post-hydration drying improves initial quality but reduces longevity of primed bitter gourd seeds. Scientia Horticulturae, v.106, p.114-124, 2005. DOI: 10.1016/j.scienta.2005.02.016.

NASCIMENTO, W.M.; ARAGÃO, F.A.S. de. Muskmelon seed priming in relation to seed vigor. Scientia Agricola, v.61, p.114-117, 2004. DOI: 10.1590/S0103-90162004000100019.

NASCIMENTO, W.M.; LIMA, L.B. Condicionamento osmótico de sementes de berinjela visando a germinação sob temperaturas baixas. Revista Brasileira de Sementes, v.30, p.224-227, 2008. DOI: 10.1590/S0101-31222008000200029.

REGRAS para análise de sementes. Brasília: Ministério da Agricultura, Pecuária e Abastecimento, 2009. 399p.

REIS, R. de G.E.; GUIMARÃES, R.M.; VIEIRA, A.R.; GONÇALVES, N.R.; COSTA, V.H. Physiological quality of osmoprimed eggplant seeds. Ciência e Agrotecnologia, v.36, p.526-532, 2012. DOI: 10.1590/S1413-70542012000500005.

RUDRAPAL, D.; NAKAMURA, S. The effect of hydration-dehydration pretreatments on eggplant and radish seed viability and vigor. Seed Science and Technology, v.16, p.123-130, 1988.

SANTOS, M.C.A.; AROUCHA, E.M.M.; SOUZA, M.S. de; SILVA, R.F. da; SOUSA, P.A. de. Condicionamento osmótico de sementes. Revista Caatinga, v.21, p.1-6, 2008. 
SCHWEMBER, A.R.; BRADFORD, K.J. Drying rates following priming affect temperature sensitivity of germination and longevity of lettuce seeds. HortScience, v.40, p.778-781, 2005.

SEDGHI, M. Changes in the activity of antioxidant and glyoxylate cycle enzymes of hydro-primed Calendula officinalis (L.) seeds after re-drying temperature stress. Journal of Stress Physiology and Biochemistry, v.9, p.279-286, 2013.

SILVA, P. de A.; DINIZ, K.A.; OLIVEIRA, J.A.; VON PINHO, E.V. de R. von. Análise fisiológica e ultra-estrutural durante o desenvolvimento e a secagem de sementes de soja. Revista Brasileira de Sementes, v.29, p.15-22, 2007. DOI: 10.1590/ S0101-31222007000200003.

SIVASUBRAMANIAM, K.; GEETHA, R.; SUJATHA, K.; RAJA, K.; SRIPUNITHA, A.; SELVARANI, R. Seed priming: triumphs and tribulations. The Madras Agricultural Journal, v.98, p.197-209, 2011.
SOEDA, Y.; KONINGS, M.C.J.M.; VORST, O.; VAN HOUWELINGEN, A.M.M.L.; STOOPEN, G.M.; MALIEPAARD, C.A.; KODDE, J.; BINO, R.J.; GROOT, S.P.C.; VAN DER GEEST, A.H.M. Gene expression programs during Brassica oleracea seed maturation, osmopriming, and germination are indicators of progression of the germination process and the stress tolerance level. Plant Physiology, v.137, p.354-368, 2005. DOI: 10.1104/ pp.104.051664.

VARIER, A.; VARI, A.K.; DADLANI, M. The subcellular basis of seed priming. Current Science, v.99, p.450-456, 2010.

VERTUCCI, C.W.; FARRANT, J.M. Acquisition and loss of desiccation tolerance. In: KIGEL, J.; GALILLI, G. (Ed.). Seed development and germination. New York: M. Dekker, 1995. p.237-271.

WU, X.; LIU, H.; WANG, W.; CHEN, S.; HU, X.; LI, C. Proteomic analysis of seed viability in maize. Acta Physiologiae Plantarum, v.33, p.181-191, 2011. DOI: 10.1007/s11738-010-0536-4.

Recebido em 9 de agosto de 2013 e aprovado em 30 de outubro de 2013 